\title{
EL TEATRO COMO INTERVENCIÓN FEMINISTA ANTIRRACISTA. REFLEXIONES EN TORNO A LAS OBRAS DE TEATRO RAÍz DE ÉBANO Y FLORES AMARILLAS
}

\author{
Theater as Anti-Racist Feminist Intervention. Reflections on the plays Ebony Root and Yellow \\ Flowers
}

\section{Astrid Yulieth Cuero-Montenegro}

\begin{abstract}
Resumen: En este artículo reflexiono sobre la relación entre cultura, arte y política feminista antirracista a partir de mi participación en el Teatro-Foro Género y Racismo realizado en Bogotá en 2011. A través del análisis de dos obras de teatro y de reflexiones teóricas sobre las articulaciones entre sexismo y racismo, sugiero la posibilidad de pensar el teatro como una forma de intervención feminista antirracista. Considero la intervención como una forma de crear conciencia sobre el racismo que experimentamos como mujeres y como cuerpos racializados. Finalmente, sitúo el teatro como un acto estético y político, con potencial para provocar el cuestionamiento de las relaciones coloniales de poder y de los mecanismos de opresión clasistas, racistas y sexistas.
\end{abstract}

Palabras clave: teatro, participación política, feminismo, racismo, sexismo, intervención feminista.

Abstract: In this article I reflect on the relationship between culture, art and anti-racist feminist politics, based on my participation as a speaker in the Theater-Forum Gender and Racism held in Bogota in 2011. Through the analysis of two plays, and in light of theoretical reflections on the interconnections between sexism and racism, I discuss the interventionist role of feminist, antiracist theater, and consider such intervention as a way to raise awareness of racism and anti-feminism as experienced corporally by women. Finally, I look at theater as an aesthetic and political event with great potential for stimulating the questioning of colonial power relations and the mechanisms of classist, racist and sexist oppression.

Keywords: theater, political participation, feminism, racism, sexism, feminist intervention.

Astrid Yulieth Cuero Montenegro. Feminista antirracista afrocolombiana. Estudiante de doctorado en el posgrado en Estudios e Intervención Feminista del Centro de Estudios Superiores de México y Centroamérica de la Universidad de Ciencias y Artes de Chiapas (CESMECAUNICACH), México. Temas de especialización: feminismo negro y decolonial, feminismo marxista y materialista, trabajo feminizado e industria maquiladora. Correo electrónico: astridcuero850@gmail.com.
Enviado a dictamen: 30 de agosto de 2016

Aprobación: 20 de marxo de 2017.

Revisiones: 1 . 


\section{Introducción}

E presente artículo tiene como objetivo reflexionar sobre el teatro como una posibilidad de intervención feminista desde posiciones antirracistas y decoloniales. A partir de mi experiencia como ponente en el Teatro-Foro Género y Racismo realizado en Bogotá, Colombia, en el año 201l, indago sobre la forma en la que el teatro puede generar transformaciones tanto en las subjetividades de las mujeres actrices que representan y producen la obra, como en el público que las aprecia. De igual forma, considero la intervención feminista desde el ámbito del arte y la cultura como una metodología que, a través de la interpelación emocional que el teatro moviliza, permite la identificación o el distanciamiento con las experiencias de racismo, sexismo o clasismo representadas en escena.

Tal interpelación emocional está relacionada con la construcción de conocimiento desde la experiencia cotidiana y artística, que al ser reflexionada e interpretada puede generar cambios tanto subjetivos, como colectivos. En particular, las obras de teatro visionadas en el teatro-foro, Raízde ébano y Flores amarillas -que representan experiencias de racismo y sexismo desde el punto de vista de mujeres afrocolombianaspermiten generar cuestionamientos frente a los sistemas de opresión y visualizar posibles formas de resistencia. Cuando hablo de la importancia de las emociones en la relación entre teatro y público, me refiero al mecanismo particular de oposición e identificación que el teatro moviliza en los espectadores.

De acuerdo con André Bazin, el teatro responde a una modalidad psicológica del espectáculo que exige una conciencia individual activa, a diferencia del cine, que pide una adhesión pasiva. Este autor afirma que "el cine calma al espectador; el teatro le excita" (Bazin, 1977: 176). Es decir, que psicológicamente el teatro mueve emociones en el público porque la oposición psicológica entre actor y espectador es más fuerte que en el cine, donde lo característico es la identificación con el héroe, de manera que promueve la mentalidad de masa (Bazin, 1977: 176). Por ello, podría afirmarse que el teatro brinda más posibilidades que el cine para tomar distancia y cuestionar lo representado en una obra. Sin embargo, como señala Bazin, en estas dos formas de arte, teatro y cine, se puede atenuar la oposición individual y la identificación de masa.

Los modos de narración en el teatro y el cine son formas ideológico-políticas de representar el mundo a través de las cuales se pueden manipular sentimientos y emociones - la experiencia-. La manipulación hace uso de la naturalización de estereotipos con procesos esencialistas de representación de la identidad. Por tanto, considero que una intervención feminista antirracista desde el teatro consiste en una interpelación emocional a los espectadores y espectadoras durante la apreciación de una obra, lo que permite generar distancia, conciencia y cuestionamiento frente a las experiencias representadas, al exhibir esas experiencias con todas sus contradicciones y al mostrar a los personajes como sujetos complejos.

Para desarrollar lo anterior, la estructura de este artículo se divide en cuatro partes. En la primera presento algunos antecedentes: explico en qué consistió la dinámica del teatro-foro y lo que significó para mí la experiencia de participación como ponente y comentarista invitada. Posteriormente realizo un análisis de las obras de teatro retomando los conceptos definidos y clarificados en el apartado de reflexión teórica. En este análisis doy cuenta de la forma como estas obras de teatro representan las experiencias racistas, sexistas y clasistas de diferentes mujeres afrocolombianas. Al final se presentan las conclusiones respecto a la forma como el teatro, y la dinámica del teatro-foro, pueden considerarse como un ejercicio de intervención feminista antirracista.

\section{Antecedentes}

El Teatro-Foro Género y Racismo se realizó los días 7, 14 y 18 de octubre de 2011 en la Universidad Nacional de Colombia, en Bogotá. Se trató de una actividad de extensión universitaria que tuvo como propósito generar un diálogo entre artistas del teatro, voces del mundo académico de las ciencias sociales y humanas, activistas 
y público no académico, con el fin de reflexionar sobre las articulaciones entre sexismo y racismo. Tal reflexión se realizó a partir del visionado de dos obras de teatro que representaban estas problemáticas en el marco de la sociedad colombiana desde experiencias de mujeres afrocolombianas y de otros cuerpos racializados.

La metodología del teatro-foro consistió en la exhibición en las dos primeras fechas de octubre de cada una de las obras, y en una tercera fecha se realizó el Foro Género y Racismo con las reflexiones-ponencias sobre las articulaciones entre sexismo y racismo. El foro contó con un público variado integrado por activistas, estudiantes universitarios y las actrices y actores de las obras, y en su desarrollo surgieron preguntas e intervenciones de diferente tipo en torno a la relación entre arte, política y academia. Entre los panelistas invitados ${ }^{2}$ había una variada selección de mujeres y hombres artistas, actrices, académicos sociales, periodistas, investigadores culturales, etnoeducadores y críticos de arte interesados principalmente por el análisis del racismo y el sexismo, la producción artística afro y la acción política.

La invitación a participar en las actividades del Teatro-Foro Género y Racismo ${ }^{3}$ me enfrentó a la realización de un ejercicio que nunca antes había hecho, o por lo menos no de forma elaborada: producir un escrito desde la transdisciplinariedad, articulando los conocimientos aportados por el arte, las ciencias sociales y la propia experiencia personal y política en torno al sexismo, el racismo y el clasismo. Mi participación en el teatro-foro ha sido una de mis experiencias académicas y políticas más enriquecedoras y agradables, ya que me enfrentó al reto de producir una reflexión académica crítica a partir del visionado de la puesta en escena de dos obras de teatro que trataban sobre las articulaciones entre el sexismo, el racismo y el clasismo.

Actualizo esta reflexión para responder a una pregunta: la posibilidad de considerar la actividad del teatro-foro como una forma de intervención feminista antirracista desde el arte, en específico desde el teatro. Además, esta pregunta se encuentra ligada a una serie de reflexiones que he venido haciendo desde hace por lo menos seis años sobre la centralidad de la experiencia en el proceso de construcción de conocimiento para el feminismo negro y antirracista. Tomar en consideración la experiencia vivida y reflexionada resulta aquí fundamental en tanto estimo que no sólo se construye conocimiento desde el ámbito académico y científico, sino también desde creaciones artísticas como el teatro, de manera que las reflexiones generadas a partir de la experiencia serían el medio a través del cual se constituyen las prácticas políticas tanto desde el ámbito artístico, como desde el feminismo.

Bazin afirma que: "[...] la obra de arte escapa a su creador y va más allá de sus intenciones conscientes, en proporción a su calidad" (1977: 154). Con estas palabras refiere a la forma como una obra artística nos interpela en nuestras emociones, así como en nuestros conocimientos intelectuales, académicos y de experiencia vivida, de manera que la intención y el significado que su creador o creadora le ha otorgado se le escapa, y una parte de esa interpretación recae en los espectadores. Como ya afirmaba el propio Bazin (2011), la obra misma adquiere sentido sólo hasta que entra en relación y comunicación directa con el público. Sólo allí la creación artística se realiza completamente. Por ello, reflexioné que precisamente uno de los retos y desafíos epistemológicos que nos presenta el feminismo negro y antirracista es el de pensar la construcción de conocimiento desde la experiencia. Ese conocimiento experiencial hace posible una lectura crítica sobre la interpelación del contenido de una obra de teatro en nuestros cuerpos, que viven las opresiones, reflexionan sobre ellas y las resisten.

Así, como mujer afrocolombiana, construyéndome como feminista en diferentes espacios académicos, políticos y cotidianos, consideré que podía construir una reflexión desde la experiencia y la academia de lo que las obras de teatro Raíz de ébano y Flores amarillas me interpelaron emocional e intelectualmente. De este modo, la apuesta por entrelazar los conocimientos y emociones que generan el arte, las ciencias sociales y mi experiencia como feminista antirracista en un escrito reflexivo resultó emocionante y desafiante para mí. En este sentido, presento a continuación una breve reflexión teórica sobre los problemas de la raza y el 
racismo y su articulación con el género y el sexismo, para luego presentar un análisis reflexivo sobre el contenido mismo de las obras de teatro y lo que generaron en mí experiencial e intelectualmente.

\section{Algunas reflexiones teóricas en torno a las articulaciones entre sexismo y racismo}

Las dos obras de teatro, Raíz de ébano y Flores amarillas, presentadas en el marco del Teatro-Foro Género y Racismo coinciden en mostrar diferentes situaciones de opresión en las que está presente la articulación entre sexismo y racismo; por tanto, considero pertinente aclarar lo que entiendo por cada uno de estos conceptos antes de introducirme en el análisis de las obras. Me sitúo en el debate decolonial y de género, en tanto coincido con la postura del feminismo negro y antirracista respecto a la comprensión de la simultaneidad de las opresiones y su codependencia. Sexismo y racismo forman parte de una coconstrucción de carácter colonial que ha configurado la dominación y el sometimiento actual de las poblaciones racializadas - afro e indígena- en Latinoamérica.

Considero que entender la experiencia afrodescendiente, que es la representada principalmente en las obras de teatro, implica dar cuenta de la forma como los sujetos racializados fueron considerados no humanos en el proceso de colonización de América. El sistema moderno/colonial de género, como lo denomina María Lugones, no sólo definió la diferencia en torno a la jerarquía hombre y mujer —en cuanto al sexo y el género-, sino también en cuanto a la jerarquía entre lo humano y no humano - la raza - (Lugones, 201la: 798). De esta manera, tanto el género está racializado, como la raza está generizada. Por ello, el feminismo decolonial cuestiona radicalmente las relaciones de poder entre mujeres, basadas en privilegios que son de raza, clase y régimen heterosexual principalmente.

Como expresara la Orisha Naná interpretada por la actriz Catalina Mosquera en la obra de teatro Flores amarillas, las diferencias en esta sociedad se han edificado sobre la base de relaciones y condiciones de desigualdad de diferentes tipos, y son construcciones sociales producto de las relaciones de poder y los sistemas de opresión. Tales diferencias configuran a los sujetos y establecen jerarquías entre ellos o entre determinados grupos sobre la base de distintos parámetros como la clase, la raza, el sexo o el género. Los discursos de poder naturalizan tales diferencias y jerarquías por vía de la normalización de las que se construyen como hegemónicas y la exclusión de las consideradas inferiores y abyectas (Foucault, 1998).

El género entonces es una de estas diferencias producida en el marco de las relaciones de poder entre los sexos, en los cuerpos construidos como hombres y mujeres, enfatizando el carácter cultural de los roles que se ha asignado a ambos (Scott, 2008: 65). Con el concepto de género se intentó explicar que las relaciones de desigualdad y dominación entre hombres y mujeres no tenían un fundamento biológico, sino un fundamento social, a pesar de que se ha considerado que el sexo sí tiene una realidad biológica. En este sentido, cuando se han realizado analogías entre las relaciones de sexo, clase y raza, algunos autores como Aníbal Quijano han afirmado que, aunque es clave la distinción entre sexo y género, no se puede igualar a la distinción entre color de piel y raza.

Quijano (2000) afirma que el género, al igual que la raza, designan construcciones sociales que no están determinadas exclusivamente por la biología y la anatomía. Para este autor, el sexo sí tiene una realidad biológica y de alguna forma fundamenta las relaciones de género, mientras que el color de piel en realidad no es el fundamento biológico de la raza ya que, a diferencia del sexo, no tiene realidad biológica (Quijano, 2000: 379). Sin embargo, coincido con la afirmación de Lugones respecto de que el sexo es también una construcción social de carácter colonial que ha biologizado ciertos aspectos anatómicos relacionados con la sexualidad.

De hecho, tales diferencias sexuales entre hombres y mujeres, basadas en órganos anatómicos como el pene y la vagina, entre otros, no aparecían claramente en algunas civilizaciones africanas, americanas o incluso orientales antes del proceso de colonización de América. ${ }^{4}$ Por tanto, no sólo el género, sino también el sexo, son construcciones sociales y culturales producto 
de la matriz colonial moderna y capitalista (Lugones, 2008: 78). El análisis de Lugones desde el feminismo decolonial permite comprender que el género implica construcciones raciales y de clase; en este sentido, la organización moderna capitalista no sólo se basó en la explotación y dominación de clase y raza, sino que también el género y el sexo forman parte de esas relaciones de poder que han sido biologizadas para ocultar sus efectos opresivos (Lugones, 2008: 81-82).

El racismo entonces se basa en la creencia de la existencia de "razas puras" y "razas degradadas", por lo que determinados pueblos o contingentes de humanos serían considerados como superiores y otros como inferiores. Pero en realidad las "razas" no existen en un sentido biológico y, como ha mostrado Quijano (2000), la "raza" es una construcción social e ideológica que fue impuesta en el proceso de colonización europea en América. La raza es, pues, un parámetro diferenciador, clasificador y jerarquizante para explotar y ejercer dominación sobre las poblaciones afrodescendientes e indígenas.

Aunque las razas no tienen realidad biológica, sus efectos ideológicos y materiales siguen vigentes y adoptan formas nuevas dependiendo de los contextos (Lozano y Peñaranda, 2007: 718). Como señala Ochy Curiel, el fenómeno del racismo es muy importante porque determina la jerarquía de género (2005), y este ha sido precisamente uno de los problemas de la categoría de género de la que se han apropiado las feministas blanco-mestizas de origen burgués y clase media, ya que se considera a las mujeres como categoría universal y, por tanto, se pasan por alto las diferencias y desigualdades entre las mismas mujeres, lo cual es importante porque el género siempre se encuentra articulado a otras formas de dominación.

En este sentido, los aportes de la teoría del black feminism, desarrollada principalmente en Estados Unidos, son fundamentales para entender las articulaciones entre el género y el racismo como dimensiones de la interseccionalidad de las opresiones, o lo que Patricia Hill Collins ha denominado como la matriz de los sistemas de opresión (1990). Como repetidamente ha señalado Viveros, la interseccionalidad no refiere a una sumatoria de opresiones, sino que lo interseccional es la experiencia misma de dominación, de manera que las articulaciones entre sexismo y racismo constituyen, entonces, una experiencia múltiple (Viveros, 2011: 6-7).

Considero que una posición feminista antirracista asume que las opresiones por raza, clase, sexo y género coexisten, teniendo en cuenta que en determinados momentos o circunstancias concretas, y dependiendo de los contextos, algunas dimensiones de estas opresiones pueden tener más peso que otras. Sin embargo, creo que a partir de la reflexión y elaboración política de estas diferencias basadas en los parámetros de la raza, la clase, el sexo o el género, es posible generar transformaciones en estos sistemas de opresión que modelan nuestra existencia.

Tales transformaciones tienen que ver con la posibilidad de agencia, la cual entiendo, en el sentido de Lugones, como el proceso de configuración de una subjetividad activa, como el ejercicio de una política de lo público en la que el sujeto puede llegar a ser consciente de la construcción de sí mismo (Lugones, 201lb: 109). La agencia implica la participación creativa en el proceso de construcción del sí mismo como sujeto, proceso en el que éste tiene la posibilidad de dudar y cuestionarse las opresiones en las que está inscrito y las normas que se le imponen. Con esta guía, a continuación destaco algunos de los aspectos más importantes de la puesta en escena de las obras de teatro Raíz de ébano y Flores amarillas, en relación con las reflexiones que proponen en torno a la articulación entre sexismo y racismo.

\section{Análisis de la obra de teatro Raíz de ébano del grupo Diokaju}

El grupo de teatro Diokaju Generación Arte Afro fue creado por Catalina Mosquera y Julián Díaz, una pareja de artistas afrocolombianos con formación en actuación y danza contemporánea, oriundos de Bogotá y de Candelaria (Valle del Cauca), respectivamente. Desde 2009 aproximadamente este grupo de teatro viene produciendo obras de teatro, de danza y de danza-teatro. Además, imparten talleres en los que, a 
través de técnicas escénicas contemporáneas, se recrean diferentes elementos de la tradición afrocolombiana. Algunas de las apuestas del proyecto artístico del grupo Diokaju van encaminadas a la revaloración de la memoria ancestral afrocolombiana y la diversidad étnica. Usan el lenguaje escénico como un medio para crear conciencia creativa y de vida.

La obra de teatro Raíz de ébano narra la historia de tres mujeres negras migrantes en Bogotá: Agripina Moreno, Ana Ruth Díaz y Alba Nelly Mina, mayores de 50 años y oriundas del Pacífico colombiano, que pertenecen a dos generaciones distintas. Los personajes interpretados por las tres actrices están basados en sus propias historias personales, y en la obra se conservan sus nombres reales. Agripina Moreno, madre de la directora de la obra, Catalina Mosquera, es una mujer de 60 años que se vio obligada a abandonar San Martín de Purré, un corregimiento del departamento del Chocó, a la edad de 18 años, porque su padre quería casarla en contra de su voluntad con un hombre del pueblo mucho mayor que ella. Ana Ruth Díaz, madre del director de la obra, Julián Díaz, de 54 años de edad, migró de Candelaria (Valle del Cauca) a los 13 años hacia la capital del país, Bogotá. En esa ciudad buscó el mejoramiento de su condición socioeconómica ya que hasta entonces había sufrido de múltiples inhibiciones y carencias. Por último, Alba Nelly Mina, de 50 años, salió de Puerto Tejada (Cauca) junto a su compañero en busca de mejores oportunidades. Estas tres historias de vida y de migración a la gran ciudad se representan en la obra a través del rescate de la memoria ancestral de las protagonistas haciendo uso de las danzas tradicionales del Pacífico afrocolombiano como la jota chocoana, el currulao y la percusión de origen africano.

La puesta en escena de la obra Raíz de ébano es relativamente sencilla, ya que prácticamente los únicos elementos que acompañan las escenas son unas palanganas de aluminio ${ }^{6}$ que cada actriz porta a lo largo de la representación. A pesar de esa aparente sencillez — son sólo tres actrices en escena-, el contenido de la obra tiene muchísima fuerza. Estas tres mujeres con sus voces, sus historias, sus movimientos y su canto llenan todo el escenario. Las palanganas de aluminio simbolizan uno de los instrumentos de trabajo que han usado muchas mujeres negras en Colombia para su sobrevivencia económica, ya sea para vender frutas o cocadas, para lavar ropa para otras familias o como bateas para encontrar oro en los ríos.

Aunque la propuesta del teatro-foro se dirigía a leer estas obras de teatro a la luz de la articulación entre el género y el racismo, considero que, en el caso particular de esta obra, las experiencias de estas mujeres negras están muy ligadas a las desigualdades de clase social por la carencia de recursos económicos, esto porque su migración a Bogotá se desarrolló en un entramado de carencias económicas que acompañan las experiencias de racismo y sexismo que motivan la salida de sus lugares de origen. Es importante resaltar que la historia de Agripina Moreno, mujer de 60 años, chocoana, es clara sobre el fenómeno del sexismo, siendo el casamiento no deseado al que quería forzarla su padre una de sus expresiones porque responde a la ideología de que el mejor destino para una mujer joven es el matrimonio, y mucho mejor si es con un hombre mayor que la sostenga. Como expresaba una de las actrices: "dicen que el esposo es el segundo padre de una mujer".

Con respecto a los elementos que permiten contar cada una de las historias de estas mujeres, me interesa destacar el papel asignado a las palanganas de aluminio en el desarrollo de la obra. Éstas, como elemento simbólico de los diferentes tipos de trabajo desempeñados por algunas mujeres afrocolombianas, tuvieron un fuerte impacto emocional para mí, sobre todo por la coreografía ejecutada por las actrices, que movían los platones al ritmo de la música del Pacífico colombiano. Hago énfasis en el simbolismo de las palanganas porque en una de las escenas, casi hacia la mitad de la obra, las actrices alinean las tres palanganas, lo que simboliza además el cruzamiento de las historias de estas tres mujeres, su punto de convergencia. En ese momento es cuando mencionan las tres frases que cambiaron el rumbo de las vidas de estas tres mujeres: “icuándo vienes?", "ite vas a ir para Bogotá?", "lo que vas a hacer, no lo hagas". La escena marca un momento de ruptura en la trayectoria individual de sus historias, y al mismo tiempo el momento de su unión. 
Considero excelente la forma en la que ha sido construida esta escena porque marca de manera profunda lo difícil que es para las mujeres tomar decisiones de este tipo, que implican un cambio de vida profundo, como trasladarse a un lugar en el que probablemente no conozcan a nadie. En general, en esta sociedad patriarcal en la que vivimos, a las mujeres no se nos enseña a tomar decisiones, porque precisamente una de las formas en la que se configura la subordinación femenina es a través de impedirnos la toma de decisiones, es decir, minando nuestra autonomía. El racismo, el sexismo y el clasismo influyen en la carencia de apoyo de redes de amigas o familiares, que en ciertas situaciones pueden limitar la búsqueda de nuestro propio camino.

La escena marca entonces lo difícil que fue para estas tres mujeres negras tomar la decisión de migrar a Bogotá, pero al mismo tiempo señala la fuerza que sacaron de su interior para hacer frente a sus miedos y a sus temores al cambio. Tuvieron la capacidad de tomar esa decisión y así comenzar a elegir el rumbo de sus vidas. Así, lo que une estas tres historias no es tanto que las protagonistas sean oriundas del Pacífico afrocolombiano y hayan migrado a Bogotá, sino que estos tres destinos se juntan por las decisiones que tomaron en la búsqueda de autonomía frente a las opresiones sexistas, clasistas y racistas que vivían, dando inicio a un proceso de resistencia conjunto en una gran ciudad como Bogotá. Por tanto, considero que una de las fortalezas de la obra Raíz de ébano se encuentra en el hecho de que las actrices estén representando artísticamente sus propias vivencias.

En este sentido, el trabajo de representar las experiencias propias en una obra de teatro es un ejercicio complejo, más cuando han estado marcadas por flagelos como el racismo, el sexismo y las desigualdades económicas de los que a veces es tan doloroso hablar. Sin embargo, es también un ejercicio catártico y liberador. Como plantea Diana Gómez, a partir del distanciamiento que permite el arte en general respecto a las experiencias personales y cotidianas, es posible elaborarlas, poniéndolas afuera, en una obra, y cuestionando las realidades en las que estamos inmersas (Gómez, 2006: 200202). El teatro entonces supone para las actrices un proceso reflexivo, de intervención subjetiva sobre sí mismas, pero, además, de intervención colectiva sobre las espectadoras y espectadores. El teatro les permite sanar el dolor, representar sus experiencias y realidades, y transformarlas al darles una nueva interpretación. Pueden posicionarse críticamente frente a los sistemas de opresión que las han limitado y hacerse conscientes de sus opciones de resistencia.

Las posibilidades del arte como forma de generación de conciencia y de reflexiones críticas sobre las propias experiencias, tanto para los artistas como para las personas del público, me remite a los conocimientos aportados por el black feminism, cuya elaboración intelectual, política y académica proviene de las propias experiencias de las mujeres afrodescendientes. En este caso, la elaboración artística de la obra de teatro parte de la interpretación y reflexividad sobre sus propias historias de vida, y en este sentido es realmente importante destacar que una de las actrices es madre de la directora de la obra, y que esta última fue creada como homenaje a ellas mismas, es decir, como una forma de visibilizar su legado de lucha para las generaciones más jóvenes de mujeres afrocolombianas.

Por último, deseo señalar que considero que en la obra que nos ocupa, Raízde ébano, se hace énfasis en la reflexión sobre la articulación entre las experiencias de sexismo y clasismo, aunque falta una mayor profundización en las experiencias de racismo de las actrices-personajes que pudieron haber motivado su migración hacia la gran ciudad. De esta manera, sin demeritar en modo alguno la calidad de la obra y el mensaje que transmite, me quedé con la expectativa de que ésta desarrollara la experiencia de estas tres mujeres ya durante su estancia en Bogotá para conocer si la ilusión de la búsqueda de progreso se cumplía o no, y qué avatares en términos de obstáculos relacionados con el sexismo, el racismo y el clasismo debieron enfrentar para cumplir sus objetivos y establecerse de manera permanente en esa ciudad. 


\section{Flores amarillas del grupo Génesis Teatro}

El grupo Génesis Teatro fue creado en el año 2007, por lo que cuenta ya con una larga trayectoria artística en Colombia. Está integrado por Laura Rodríguez Duque y Carlos Eduardo Suárez Cifuentes, este último director de los siete montajes teatrales realizados hasta el momento por el grupo. Génesis Teatro se define como un colectivo artístico interesado en desarrollar propuestas escénicas que lleven al público nuevas visiones tanto de su propio entorno, como de sí mismos.? Flores amarillas ${ }^{8}$ es una obra de teatro contemporánea que narra la historia de Yomaira, una niña de 10 años, quien sufrió un acto de discriminación por parte de su profesora de colegio. Por tal razón, la Orisha Naná, abuela poseedora de la sabiduría ancestral de los afrodescendientes, se presenta ante la niña y le cuenta cuatro historias para que comprenda cómo llegaron sus antepasados afrodescendientes a América y las vicisitudes que tuvieron que enfrentar a través del tiempo.

La experiencia de discriminación de Yomaira ${ }^{9}$ se basaba en que su profesora consideró que esta niña, mujer y negra, no podía y no debía llegar a ser poeta. Las historias presentadas en esta obra están guiadas por la historia principal de la niña, Yomaira, quien actúa como testigo de los diversos tipos de opresión que sufren los descendientes de la diáspora africana, incluida ella misma. Sobre las articulaciones entre el género y el racismo, lo primero que quiero señalar es que la experiencia de discriminación en la escuela por parte de una profesora que no valora el saber de su alumna muestra paradójicamente la gran necesidad e interés de las poblaciones afrodescendientes por aprender; la gran pasión que sentimos por adquirir conocimiento y que, en el caso de Yomaira, desea expresar a través del arte, de la poesía.

Y esa necesidad vital de conocimiento parte precisamente de los mismos rezagos derivados de la experiencia deesclavitud que se manifiestan actualmente en el racismo estructural y en la discriminación cotidiana presentes en la sociedad colombiana. Habría que decir que en el caso de las mujeres afrodescendientes existe una doble negación, una doble exclusión en el acceso a ese conocimiento. En este tenor, Angela Davis da cuenta de cómo la búsqueda del conocimiento ha sido una prioridad para la población negra en Estados Unidos desde que se encontraba en condiciones de esclavitud porque el acceso al conocimiento cumplía un papel emancipador. Y, precisamente por ello, uno de los pilares de la esclavitud y del racismo actual, que se ha desprendido de esta experiencia, ha sido negar el acceso a la educación a las mujeres y hombres afrodescendientes, principalmente a los conocimientos críticos generados por las propias poblaciones afro o en condición de subalternidad (Davis, 2004: 107).

A partir del caso de la niña Yomaira se evidencia la continuidad de los rezagos de la esclavitud con respecto al papel de la escuela y el sistema educativo, como instituciones a través de las cuales se reproduce el racismo estructural y cotidiano. En Colombia, el sistema educativo mismo está impregnado de racismo, de manera que no basta con exigir acceso a la educación si la que recibimos sigue estando basada en modelos occidentales, coloniales y eurocéntricos excluyentes, en modelos carentes de crítica reflexiva sobre las condiciones sociales, culturales y económicas en las que vivimos las poblaciones afrodescendientes.

Continuando con la historia de Yomaira, es importante resaltar cómo se vincula su pasión por aprender con la inspiración que le brindan los Orishas. ${ }^{10}$ La Orisha Naná de las flores amarillas guía el camino de Yomaira en su aprendizaje tanto educativo, como de vida. Podría decirse, entonces, que la Orisha va mostrando a Yomaira las diferentes situaciones en las que el racismo y el sexismo se articulan y tienen presencia. Una de estas situaciones de discriminación se relaciona con el acceso al empleo, y está representada en la obra en una escena en la que una mujer afro presenta su hoja de vida para un trabajo, y en la que el empleador le advierte que no hay vacantes en el área de aseo y cafetería.

Precisamente la legitimación de los estereotipos sobre los trabajos desarrollados por algunas mujeres afrodescendientes reproduce el racismo y su exclusión de los empleos calificados, que en algunas ocasiones 
pueden ofrecer mejores condiciones en el mercado laboral (Cuero, 2008). De esta manera, se considera que existen trabajos que deben ser desempeñados por las mujeres afro, como si ésta fuera una disposición de la naturaleza. En el caso de otro personaje de la obra, una mujer negra empleada doméstica, se evidencia de forma concreta la falsa unidad de la categoría "mujeres" como categoría universal que nos recoge a todas, cuando se considera que compartimos la misma opresión de género. Sin embargo, el efecto de la clase social y del racismo da cuenta de que no compartimos las mismas condiciones de existencia. Como muestra una escena de la obra, la "liberación" de la mujer mestiza-blanca descansa sobre la base de la opresión de la mujer negra; la patrona puede dedicarse a un estilo de vida superficial porque el trabajo doméstico queda encargado a una mujer negra.

Es importante destacar que en una buena parte de las escenas es evidente el acercamiento investigativo de los actores y actrices a la religión yoruba, lo que se expresa en la forma como actúan, en las manifestaciones de los Orishas en el mundo de los vivos y de los muertos, y en la estrecha relación que esta religión contempla entre el mundo de la vida y el mundo de la muerte. En este sentido, la conexión espiritual de la niña Yomaira con la Orisha Naná, que se constituyó en un proceso de aprendizaje sobre las experiencias de discriminación de hombres y mujeres afro a lo largo de la historia y que permite explicar su propia historia, le ofrece la posibilidad de situarse de nuevo en el presente. Ella se levanta del suelo y toma en sus manos el papel en el que estaba escrita su poesía y que su profesora rechazó. En ese momento, la visión de las formas de opresión pasadas y actuales que ha presenciado Yomaira y que le han sido mostradas a través de los Orishas le da un nuevo impulso y esperanza para cumplir sus deseos y alcanzar sus metas. Se convierte en una inspiración para continuar alimentando su vocación de poeta, para no abandonar su amor por el conocimiento y para continuar el camino de liberación iniciado por sus antepasados. La Orisha de las flores amarillas le ha presentado a Yomaira la historia de la esclavitud, del racismo y de la discriminación de sus ancestros, y es por ello que debe perpetuar su legado de resistencia. Se le concede así, en esta obra, una especial importancia al conocimiento del pasado ancestral, en el caso de Yomaira para transformar su propia historia y la del pueblo afro en general.

Finalmente, en el momento del intercambio con el público no pocas participantes mencionaron la forma en la que se habían sentido impactadas por las situaciones representadas en ambas obras de teatro. Principalmente, las mujeres asistentes al foro hablaron de cómo durante las representaciones rememoraron sus propias experiencias de racismo y sexismo. Ese es el potencial del teatro, el de impactar emocionalmente y construir conocimientos experienciales que luego puedan elaborarse intelectualmente para intentar llevar a cabo nuevas propuestas de transformación de realidades. Como señala Gómez, "con el teatro la gente se va furiosa, cuestionada con algo que le va generando lecturas y cambios" (2006: 201).

\section{Conclusiones}

Considero que el teatro, y un espacio como el teatro-foro, tienen el potencial de convertirse en metodologías de intervención social desde posiciones feministas antirracistas y decoloniales, que permiten generar transformaciones en las subjetividades de las mujeres desde el ámbito del arte y la cultura. Como señala Gómez, "el valor del teatro está en la posibilidad de generar sensibilización y reflexión sin necesidad de que sea impuesto" (2006: 201). La apreciación de una obra da espacio para la interpretación de la realidad y de su propia experiencia personal y subjetiva por la interpelación emocional e intelectual que suscita, de modo que tanto las actrices como las personas del público cuentan con la posibilidad de generar conocimientos críticos sobre sus propias realidades.

La intervención feminista antirracista consistió entonces en que las obras que formaron parte del teatro-foro representaban personajes afrodescendientes con experiencias contradictorias que no cumplían con los estereotipos racistas o sexistas. Las mujeres afro retratadas tenían agencia, tomaban decisiones y, aunque 
se enfrentaban con limitaciones, podían resistir. Estas obras de teatro muestran representaciones "otras" de las mujeres afrocolombianas que, en complemento con la metodología del teatro-foro, permiten reflexionar sobre la realidad sexista, clasista y racista, de tal manera que el público puede producir interpretaciones propias sobre la realidad representada para cuestionarla.

En este sentido resultó revelador que, en el caso de la obra Raíz de ébano, fueran las propias mujeres afro que vivieron en carne propia estos flagelos del sexismo y el racismo las que representaran de forma artística sus propias vivencias. Por ello, esta modalidad de hacer teatro también es un recurso para generar reflexión crítica y política, y para realizar una intervención feminista antirracista a un nivel subjetivo. La centralidad aquí de la categoría de experiencia, como ha sido propuesta por el black feminism, nos permite reconocer que el conocimiento artístico, académico y político puede partir de la experiencia vivida elaborada, es decir, interpretada críticamente.

En el caso de Flores amarillas, se trata de una obra de teatro con una excelente puesta en escena, en la que se percibe que es producto de una seria investigación académica y política sobre las condiciones de las poblaciones afrodescendientes en las Américas. De igual forma, la creación y puesta en escena de la obra exigió a las actrices, los actores y a su director un riguroso trabajo de creación y reflexión colectiva sobre los fenómenos del racismo y el sexismo. A pesar de que sus experiencias personales no estén explicitadas y representadas en la obra, sin duda están implicadas, en tanto el ejercicio de ponerse en la piel de personajes que tienen historias diferentes a las suyas les permite moverse de sus vivencias hacia otras realidades, e identificarse para hacer suyas esas otras experiencias.

Finalmente, puedo concluir, a partir de mi participación en el Teatro-Foro Género y Racismo, y con la apreciación de las dos obras, que definitivamente el teatro es una herramienta artística con una gran capacidad para acercarse al entendimiento de las experiencias racistas y sexistas, que además están atravesadas por otras formas de opresión. Considero que es una forma creativa para generar reflexión, sensibilizar y denunciar entre los artistas y el público amplio respecto a estas situaciones de desigualdad y exclusión. Por el impacto que estas dos obras han tenido en mí y en el público que las vio, las considero como métodos críticos y reflexivos de intervención social feminista y antirracista, pero también decolonial, en tanto que el teatro cuenta con el potencial de promover reflexiones y conocimiento críticos desde las emociones; es decir, se generan conocimientos descolonizadores en los que cuerpo e intelecto están íntimamente ligados.

\section{Notas}

${ }^{1}$ Mara Viveros, coordinadora de la Escuela de Estudios de Género, y los investigadores Franklin Gil y Mercedes Angola, fueron los coordinadores académicos del espacio de este teatro-foro. El mismo se realizó bajo la organización conjunta de la Escuela de Estudios de Género, la Facultad de Ciencias Humanas, la Escuela de Artes Plásticas y Visuales y la Facultad de Artes de la Universidad Nacional de Colombia, con el apoyo de la Agencia Española de Cooperación Internacional para el Desarrollo (AECID).

2 Los panelistas invitados fueron: Patricia Ariza, dramaturga, poeta y actriz de teatro colombiana; Alexander Cifuentes, antropólogo, especialista en poblaciones afrocolombianas; Paolo Vignolo doctor en Historia y Civilizaciones, profesor asociado de la Universidad Nacional de Colombia; María Isabel Mena, quien ha sido asesora del Ministerio de Educación Nacional para la educación afrocolombiana y para los proyectos etnoeducativos afrocolombianos, y Ángel Perea Escobar, investigador cultural y periodista afrocolombiano.

${ }^{3}$ La invitación me llegó a través de Mara Viveros, quien conocía mi trabajo como investigadora sobre las sexualidades de mujeres negras en el suroccidente colombiano y como activista feminista en el movimiento de mujeres negras y en el movimiento afroestudiantil mixto de Cali. Actualmente Mara Viveros asumió de nuevo el cargo como coordinadora de la Escuela de Estudios de Género de la Universidad Nacional de Colombia. 
4 Es importante aclarar que Lugones ha recibido algunas críticas por estos argumentos. Feministas decoloniales como Rita Segato y Breny Mendoza tienen interpretaciones diferentes sobre la relación entre género y patriarcado. Segato considera que la diferenciación de género es anterior al proceso de colonización europea en América, en tanto señala que todos los mitos de origen de distintas sociedades subordinan a las mujeres. Para esta autora, en las poblaciones afro e indígenas existía un patriarcado de baja intensidad anterior a la colonización de América, y posterior a este proceso se profundizó y constituyó el patriarcado colonial moderno (Segato, 2010). Por su parte, Mendoza prefiere apelar al concepto de pacto social de género para dar cuenta de la forma como la racialización de las relaciones, en particular las relaciones de trabajo, se configuró sobre la base de un pacto social entre capitalistas y obreros blancos en detrimento de los trabajadores no-blancos y noasalariados, pacto que también excluyó inicialmente a las mujeres blancas. Es decir, que Mendoza apoya los planteamientos de Lugones en su crítica a Quijano, pero dando más peso a la categoría de clase en la interseccionalidad entre raza y género (Mendoza, 2014: 23-27).

${ }^{5}$ Ficha técnica de la obra Raíz de ébano. Grupo: Diokaju. Directora: Catalina Mosquera. Actuación: Agripina Moreno, Ana Ruth Díaz y Alba Nelly Mina. Coreografía: Catalina Mosquera. Duración de la obra: 40 minutos. Arte dramático, danza, teatro de sala.

6 Las palanganas de aluminio han sido usadas principalmente por las mujeres afro de San Basilio de Palenque, en la costa Caribe de Colombia, para la venta de frutas, llevándolas sobre sus cabezas. También son usadas por mujeres de diferentes etnias africanas.

${ }^{7}$ Génesis Teatro ha ganado diferentes premios como el de la Convocatoria al I Festival de Jóvenes Creadores Teatro Quimera 2013 y el de Programación Artística de la Fundación Gilberto Alzate Avendaño, para el periodo comprendido entre junio y septiembre del año 2013.

${ }^{8}$ Ficha técnica de la obra Flores amarillas. Grupo: Génesis Teatro. Dirección y dramaturgia: Carlos Eduardo Suárez Cifuentes. Investigación: Franklin Gil Hernández.
Actuación: Danny Suley Castro, Catalina Mosquera, Laura Rodríguez Duque, Carlos Eduardo Suárez, Harry Mina y Franklin Gil Hernández. Duración de la obra: 55 minutos. Arte dramático, teatro de sala.

${ }^{9}$ El personaje está basado en un caso real de una niña afro, recogido en una investigación por el Grupo de Estudios Afrocolombianos de la Universidad Nacional de Colombia.

${ }^{10}$ Tal y como lo define Manuel Zapata Olivella en el cuaderno de bitácora de su novela Changó el Gran Putas, los Orishas son las deidades más importantes y poderosas de la religión yoruba. El autor presenta la genealogía de las catorce deidades más importantes del panteón yoruba. Los Orishas están relacionados con los ancestros porque se considera que estos últimos, después de muertos, conviven con los primeros. La idea de los ancestros está relacionada con la religión bantú, que considera que "el difunto goza de una energía plena de inteligencia y voluntad", de manera que en las religiones yoruba y bantú no existe una separación radical entre el mundo de los muertos y el de los vivos.

\section{Referencias bibliográficas}

Bazin, André (1977). El cine de la crueldad. De Buñuel a Hitchcock. Bilbao: Mensajero.

Bazin, André (2001). ¿Qué es el cine? Madrid: Rialp.

Cuero, Astrid Y. (2008). "Los efectos de la discriminación de la mujer afrocolombiana en el acceso al empleo en la ciudad de Cali". En Red Nacional de Mujeres Afrocolombianas "Kambirí" (eds.). Ser mujer afro en Cali. Vivencias, convivencias y resistencias. Estudio de línea de base. Cali: Publicaciones Ébano.

Curiel, Ochy (2005). "Identidades esencialistas o construcción de identidades políticas. El dilema de las Feministas Negras". En Ginetta E. B Candelario (comp.), Miradas desencadenantes. Los estudios de género en la República Dominicana al inicio del tercer milenio. Santo Domingo: INTEC.

Davis, Ángela (2004). Mujeres, raza y clase. Madrid: Akal.

Foucault, Michel (1998). Historia de la Sexualidad I. La voluntad de saber. México: Siglo Veintiuno. 
Gómez Correal, Diana M. (2006). “'Aquí fue Troya'. Mujeres, teatro y agencia cultural”. En Tabula Rasa, 5, julio-diciembre: 193-208.

Hill Collins, Patricia (1990). Black Feminist Thought: Knowledge, Consciousness, and the Politics of Empowerment. Boston: Unwin Hyman.

Lozano Lerma, Betty Ruth y Bibiana Peñaranda (2007). "Memoria y reparación iy de ser mujeres negras qué?" En Claudia Mosquera Rosero-Labbé y Luiz Claudio Barcelos (eds.). Afro-reparaciones: memorias de la esclavitud y justicia reparativa para negros, afrocolombianos y raizales. Bogotá: Centro de Estudios Sociales-Universidad Nacional de Colombia-Facultad de Ciencias Humanas. Lugones, María (2008). “Colonialidad y género". En Tabula Rasa, 9, julio-diciembre: 73-101.

Lugones, María (201la). "Hacia metodologías de la decolonialidad". En Conocimientos y prácticas políticas: reflexiones desde nuestras prácticas políticas de conocimiento situado, t. II. Chiapas, Ciudad de México: CIESAS, UNICACH, PDTG-UNMSM.

Lugones, María (201lb). "Hacia un feminismo descolonial". En La Manzana de la Discordia, 6(2), juliodiciembre: 105-119.
Mendoza, Breny (2014). "La epistemología del sur, la colonialidad del género y el feminismo latinoamericano". En Yuderkys Espinosa Miñoso (ed.), Tejiendo de otro modo: feminismo, epistemología y apuestas descoloniales en Abya Yala. Popayán: Editorial Universidad del Cauca.

Quijano, Aníbal (2000). "Colonialidad del poder y clasificación social". En Journal of World-Systems Research, VI(2), summer/fall: 342-386.

Scott, Joan (2008). Género e historia. México: FCE, Universidad Autónoma de la Ciudad de México.

Segato, Rita (2010). "Género y colonialidad: en busca de claves de lectura y de un vocabulario estratégico descolonial". En Aníbal Quijano y Julio Mejía Navarrete (eds.). La cuestión descolonial. Lima: Cátedra América Latina y la Colonialidad del PoderUniversidad Ricardo Palma.

Viveros, Mara (2011). "Género y racismo. Reflexiones a partir de investigaciones colombianas". En Seminario Conspiración Afrofemenina, GAUV y Casa Cultural El Chontaduro, Cali, Colombia.

Zapata Olivella, Manuel (1983). Changó. El gran putas. Bogotá: Oveja Negra. 